University of Nebraska - Lincoln

DigitalCommons@University of Nebraska - Lincoln

Faculty Publications from Nebraska Center for

Materials and Nanoscience, Nebraska Center Materials and Nanoscience

for (NCMN)

February 2002

\title{
Characterization of CrBN films deposited by ion beam assisted deposition
}

\author{
S.M. Aouadi \\ University of Nebraska - Lincoln \\ F. Namavar \\ Spire Corporation, One Patriots Park, Bedford, Massachusetts \\ E. Tobin \\ Spire Corporation, One Patriots Park, Bedford, Massachusetts \\ N. Finnegan \\ University of Illinois at Urbana-Champaign, Urbana, Illinois \\ R.T. Haasch \\ University of Illinois at Urbana-Champaign, Urbana, Illinois \\ See next page for additional authors
}

Follow this and additional works at: https://digitalcommons.unl.edu/cmrafacpub

Part of the Nanoscience and Nanotechnology Commons

Aouadi, S.M.; Namavar, F.; Tobin, E.; Finnegan, N.; Haasch, R.T.; Nilchiani, R.; Turner, Joseph A.; and Rohde, S. L., "Characterization of CrBN films deposited by ion beam assisted deposition" (2002). Faculty Publications from Nebraska Center for Materials and Nanoscience. 55.

https://digitalcommons.unl.edu/cmrafacpub/55

This Article is brought to you for free and open access by the Materials and Nanoscience, Nebraska Center for (NCMN) at DigitalCommons@University of Nebraska - Lincoln. It has been accepted for inclusion in Faculty Publications from Nebraska Center for Materials and Nanoscience by an authorized administrator of DigitalCommons@University of Nebraska - Lincoln. 


\section{Authors}

S.M. Aouadi, F. Namavar, E. Tobin, N. Finnegan, R.T. Haasch, R. Nilchiani, Joseph A. Turner, and S. L. Rohde 


\title{
Characterization of CrBN films deposited by ion beam assisted deposition
}

\author{
S. M. Aouadi \\ Department of Mechanical Engineering, University of Nebraska, Lincoln, Nebraska 68588-0526 \\ F. Namavar and E. Tobin \\ Spire Corporation, One Patriots Park, Bedford, Massachusetts 01730-2396 \\ N. Finnegan and R. T. Haasch \\ Center for Microanalysis of Materials, Frederick Seitz Materials Research Laboratory, University of Illinois \\ at Urbana-Champaign, Urbana, Illinois 61801 \\ R. Nilchiani and J. A. Turner \\ Department of Engineering Mechanics, University of Nebraska, Lincoln, Nebraska 68588-0526 \\ S. L. Rohde ${ }^{\text {a) }}$ \\ Department of Mechanical Engineering, University of Nebraska, Lincoln, Nebraska 68588-0526
}

(Received 20 June 2001; accepted for publication 16 October 2001)

\begin{abstract}
This article reports on the growth and analysis of $\mathrm{CrBN}$ nanocrystalline materials using an ion beam assisted deposition process. In addition, this article addresses the utilization of spectroscopic ellipsometry for in situ analysis of ternary nitrides. Coatings, with a total thickness of 1.5 $\pm 0.2 \mu \mathrm{m}$, were deposited at low temperatures $\left(<200^{\circ} \mathrm{C}\right)$ on silicon substrates using ion beam assisted deposition. These coatings were characterized postdeposition using $\mathrm{x}$-ray diffraction (XRD), atomic force microscopy (AFM), x-ray photoelectron spectroscopy (XPS), Auger electron spectroscopy (AES), visible-light spectroscopic ellipsometry (VIS-SE), infrared spectroscopic ellipsometry (IR-SE), and nanoindentation. The primary phases in the films were investigated using XRD. The surface morphology and nanocrystalline nature of the coatings (grain size of 5-7 nm) were deduced using AFM. The elemental composition and phase composition of the samples were determined from XPS and AES measurements and were subsequently deduced from the analysis of the VIS-SE data, and these correlated well. XPS, AES, and IR-SE revealed the crystal structure of the $\mathrm{BN}$ phase in the ternary compounds. The correlation of the results from these various techniques indicates that in situ SE may be a potential technique to control the growth of ternary nitride coatings in the future. The mechanical properties of the coatings were evaluated using nanohardness testing. The hardness and elastic modulus were measured to be 19-22 GPa and 250-270 GPa, respectively. (C) 2002 American Institute of Physics. [DOI: 10.1063/1.1426243]
\end{abstract}

\section{INTRODUCTION}

In the last three decades, nitride based protective coatings have been used in many applications due to their excellent wear, erosion, and corrosion resistance. ${ }^{1-3}$ More recently, the addition of boron was found to increase the high temperature stability of these hard coatings. These boron nitride films had good corrosion and wear resistance, evident from the low corrosion current density in acid environments, ${ }^{4}$ and low abrasion wear volume obtained in wear tests ${ }^{5}$ indicating the excellent potential of these coatings in industrial applications. Some of the hard transition metal boron nitride (MBN) coatings that have been recently deposited include TiBN, ${ }^{6,7}$ TiAlBN,${ }^{8}$ TiBCN,${ }^{5}$ and ZrBN. ${ }^{9}$

MBN coatings are multiphase materials that have very complex phase diagrams. The understanding and control of the phase evolution during the deposition of such complex materials is key to the fabrication of coatings with tailored properties/performance. For example, the hardness and

a) Author to whom correspondence should be addressed; electronic mail: srohde@unl.edu toughness of TiBN coatings was found to be strongly dependent on composition (20-70 GPa). ${ }^{10}$ For instance, Hammer et al. ${ }^{11}$ obtained a hardness of $55 \mathrm{GPa}$ for $\mathrm{TiBN}_{0.4}$ which consists of $\mathrm{TiN}$ and $\mathrm{TiB}_{2}$ phases. As the concentration of $\mathrm{B}$ or $\mathrm{N}$ is increased either cubic $\mathrm{BN}(c-\mathrm{BN})$ and/or hexagonal $\mathrm{BN}$ $(h$ - $\mathrm{BN})$ phases begin to form. Hexagonal $\mathrm{BN}$ is a soft material with a low coefficient of friction and would be an excellent candidate for dry machining applications. Cubic BN is a hard material that is expected to produce superhard TiBN coatings. Likewise, because of the similarities in structure and properties between $\mathrm{Ti}-\mathrm{N}$ and $\mathrm{Cr}-\mathrm{N}$ phases, $\mathrm{Cr}-\mathrm{B}-\mathrm{N}$ films can be expected to provide properties similar to $\mathrm{Ti}-$ $\mathrm{B}-\mathrm{N}$ thin films.

This paper reports on a study of CrBN coatings deposited by ion beam assisted deposition (IBAD). The only prior published work on $\mathrm{CrBN}$ coatings is that of Rother and Kappl. ${ }^{12,13}$ Their coatings were deposited using a cathodic arc discharge technique with boron concentrations in the $0.5-30$ at. \% range. The primary results of their investigations can be summarized as follows: (1) the response of asdeposited and tempered $\mathrm{CrBN}$ coatings to the penetration of an indenter was comparable for boron concentrations in the 
0\%-10\% range; (2) for coatings with a boron content of $10 \%-30 \%$ an increase in hardness with annealing was observed; and (3) grain refinement as a result of boron addition was more prominent in $\mathrm{Cr}-\mathrm{N}$ than in $\mathrm{Ti}-\mathrm{N}$ coatings.

The phase diagram of $\mathrm{CrBN}$ is very complex, even more so than that of TiBN. ${ }^{14}$ The stable phase combinations are: $\left(\mathrm{Cr}+\mathrm{Cr}_{2} \mathrm{~B}+\mathrm{BN}\right), \quad\left(\mathrm{Cr}_{2} \mathrm{~N}+\mathrm{Cr}_{2} \mathrm{~B}+\mathrm{BN}\right), \quad\left(\mathrm{CrN}+\mathrm{Cr}_{2} \mathrm{~N}\right.$ $+\mathrm{BN}), \quad\left(\mathrm{Cr}_{2} \mathrm{~B}+\mathrm{CrB}_{4}+\mathrm{BN}\right), \quad\left(\mathrm{CrB}+\mathrm{CrB}_{2}+\mathrm{BN}\right), \quad\left(\mathrm{Cr}_{5} \mathrm{~B}_{3}\right.$ $+\mathrm{CrB}+\mathrm{BN}),\left(\mathrm{Cr}_{2} \mathrm{~B}+\mathrm{Cr}_{5} \mathrm{~B}_{3}+\mathrm{BN}\right),\left(\mathrm{CrB}_{4}+\mathrm{BN}+\mathrm{B}\right),(\mathrm{CrN}$ $\left.+\mathrm{BN}+\mathrm{N}_{2}\right)$. All of these phases possess different structural and mechanical properties. Therefore, the fabrication of application specific $\mathrm{CrBN}$ hard coatings hinges on the selection of the appropriate phases and optimization of their relative percentages.

Previous studies of binary $\mathrm{Cr}-\mathrm{N}$ and $\mathrm{Ti}-\mathrm{N}$ have shown that real-time ellipsometry is a promising technique for fabricating coatings with controlled optical characteristics and thickness ${ }^{15-17}$ and may be useful in the selection of the desired elemental and phase composition during the growth of CrBN films. This method has several advantages over other real-time techniques: it is a nondestructive technique and is highly sensitive to any small variations in composition, thickness, and surface roughness. Owing to these unique characteristics, ellipsometry is rapidly becoming accepted as a technique for controling and monitoring the deposition of semiconductor, ${ }^{15,18}$ magnetic, ${ }^{19,20}$ optical, ${ }^{21,22}$ and more recently, protective coatings. ${ }^{17,18}$ To date, however, little if no ellipsometric analysis has been performed on ternary nitride coatings.

The goal of this study was to (1) investigate the properties/performance of $\mathrm{CrBN}$ coatings with different compositions and (2) to show that in situ ellipsometry is a production worthy technique for process monitoring and control of complex nitride compounds. To achieve this goal, single layer coatings were deposited by ion beam assisted deposition (IBAD) on (100) silicon wafers with different $\mathrm{CrB}_{2} / \mathrm{N}$ arrival ratio. The following techniques were used to characterize these coatings: $x$-ray diffraction (XRD), atomic force microscopy (AFM), x-ray photoelectron spectroscopy (XPS), Auger electron spectroscopy (AES), spectroscopic ellipsometry in the visible spectrum (VIS-SE), and spectroscopic ellipsometry in the infrared spectrum (IR-SE). XRD and AFM were used to analyze crystallographic structure and texture, while XPS, AES, VIS-SE, and IR-SE were used to deduce the elemental and phase composition of the deposited layers. The hardness and elastic modulus of these samples were also tested using a nanoindenter. The results from the various analytical techniques were then compared to the ellipsometric data.

\section{EXPERIMENTAL PROCEDURE}

CrBN films were deposited by IBAD on polished $\mathrm{Si}$ (100) wafers. The IBAD system consists of a 6-in. diameter Kaufmann type ion source which can be operated up to $2 \mathrm{kV}$. Films were grown reactively, via evaporation of $\mathrm{Cr}$ and $\mathrm{B}$ from two electron beam guns, with concurrent nitrogen ion beam bombardment. All coatings were deposited at a base pressure of less than $3 \times 10^{-5} \mathrm{~Pa}$, and substrate temperatures were maintained under $150^{\circ} \mathrm{C}$ at all times during the deposition process. The coatings had a total thickness of 2.0 $\pm 0.2 \mu \mathrm{m}$. In addition, an interlayer of $\mathrm{Cr} / \mathrm{CrN}$ with a thickness of $0.4 \pm 0.1 \mu \mathrm{m}$ was deposited for all of the films.

Three different sets of film deposition conditions were examined. A total of five samples were grown for each set of samples. In the first set (designated S1), Cr, and B were evaporated concurrently at rates of 3 and $1.5 \AA / s$, respectively. The film was simultaneously bombarded with a nitrogen ion beam (without any Ar mixture) at a current density of $100 \mu \mathrm{A} / \mathrm{cm}^{2}$. The second set of films (designated S2) was deposited using the same $\mathrm{Cr}$ and $\mathrm{B}$ evaporation rates, but used a $1: 4 \mathrm{Ar} / \mathrm{N}$ ion mixture at $50 \mu \mathrm{A} / \mathrm{cm}^{2}$. The third set of films (designated S3) was deposited using $\mathrm{Cr}$ and $\mathrm{B}$ evaporation rates of 2 and $1 \AA / s$, respectively. In this case the ion beam was a 1:4 $\mathrm{Ar} / \mathrm{N}$ mixture, and the ion beam current density was $100 \mu \mathrm{A} / \mathrm{cm}^{2}$. In all cases, the ion energy was $600 \mathrm{eV}$. The test results reported in this article were reproduced for the same set of samples to within 5\%.

The crystallographic structure and texture of the films were analyzed by XRD and AFM. The XRD analysis was performed using $1.54 \AA$ wavelength $\mathrm{Cu} K \alpha$ radiation with a Rigaku x-ray diffractometer and a graphite diffracted beam monochromator. All the spectra were taken with an accelerating voltage of $50 \mathrm{kV}$ and a current of $100 \mathrm{~mA}$. AFM measurements were carried out using an AutoProbe CP Microscope. The microscope is equipped with a $5 \mu \mathrm{m}$ piezoelectric scanner with a maximum lateral scan range of $5 \mu \mathrm{m}$ and a maximum vertical scan range of $2.5 \mu \mathrm{m}$.

The chemical analysis of these films was performed using XPS and AES. XPS spectra were recorded with a Kratos Axis Ultra system equipped with a variable angle probe. The background pressure and operating pressure were maintained at $3 \times 10^{-9}$ and $2 \times 10^{-8} \mathrm{~Pa}$, respectively. The samples were excited with a monochromatic $\mathrm{Al}(K \alpha)$ radiation source. This source was operated using a voltage of $15 \mathrm{kV}$ and an emission current of $20 \mathrm{~mA}$. The emission photoelectrons were collected from a $1 \mathrm{~mm}^{2}$ area. For quantitative analysis, peak areas determined after background subtraction were taken to measure relative elemental fractions after correction with the appropriate sensitivity factors provided by the manufacturer. To remove the surface oxide, the sample surfaces were etched by a $3 \mathrm{keV}$ rastered argon ion beam with a current of $0.2-0.4 \mu \mathrm{A}$. The oxygen signal was monitored until it decreased no further, and the "after" etch spectra was collected.

Auger spectra were recorded with a Physical Electronics PHI 660 scanning Auger microprobe. The background pressure and operating pressure were maintained at $5 \times 10^{-9}$ and $2 \times 10^{-8} \mathrm{~Pa}$, respectively. The samples were excited with a $\mathrm{LaB}_{6}$ Filament Electron Gun. This source was operated using a voltage of $3 \mathrm{kV}$. To remove the surface oxide, the sample surfaces were etched by a $1 \mathrm{keV}$ rastered argon ion beam.

Spectroscopic ellipsometry data in the visible range was obtained using a Woollam Co. VASE® Variable Angle Spectroscopic Ellipsometer (VASE) equipped with a WVASE32 ${ }^{\mathrm{TM}}$ data analysis software. ${ }^{23}$ Simultaneously, the system acquired a spectrum ranging from 0.7 to $5.0 \mathrm{eV}$ with $0.1 \mathrm{eV}$ 
TABLE I. Binding energies of XPS peaks recorded from standard materials.

\begin{tabular}{ccc}
\hline \hline Material & $B 1 s$ B.E. (eV) & $N 1 s$ B.E. (eV) \\
\hline $\mathrm{CrB}_{2}$ & 188.0 & \\
$\mathrm{CrB}$ & 187.7 & \\
$\mathrm{Cr}_{2} \mathrm{~B}$ & 187.5 & 397.4 \\
$\mathrm{Cr}_{2} \mathrm{~N}$ & & 396.7 \\
$\mathrm{CrN}$ & & 398.1 \\
$\mathrm{BN}$ & 190.5 & \\
\hline \hline
\end{tabular}

intervals. The minimum acquisition time was $1 / 25 \mathrm{~s}$, but typical rates were of the order of $0.5-5 \mathrm{~s}$. Data were taken using three different angles of incidence: $65^{\circ}, 70^{\circ}$, and $75^{\circ}$. IR-SE measurements were carried out using a rotatingpolarizer, rotating-compensator, Fourier-transform-based variable angle of incidence spectroscopic ellipsometer. These measurements were carried out in the wave number range between 700 and $3000 \mathrm{~cm}^{-1}$ with an angle of incidence of $70^{\circ}$.

In ellipsometry, the measured quantities are the relative amplitude attenuation $\tan \psi$ and the relative phase change $\Delta$ as a function of wavelength or energy. ${ }^{24}$ VIS-SE data were fitted by regression analysis to a film-on-substrate model as described by their thickness and their complex refractive indices. The change of the polarization of the radiation upon reflection from the surface is measured as a function of the wavelength and compared with the simulated data. In this article, only $\psi$ or $\epsilon_{1}$ data are presented to reduce the number of figures.

Film hardness was measured using a computer controlled Hysitron Triboscope ${ }^{\circledR}$ Nanomechanical testing system using a load of $5000 \mu \mathrm{N}$. The force resolution of the Triboscope ${ }^{\circledR}$ system was less than $1 \mathrm{nN}$. The displacement resolution was $\sim 0.2 \mathrm{~nm}$. The noise floor for the force was $100 \mathrm{nN}$, while the noise floor for the displacement was less than $0.2 \mathrm{~nm}$ without averaging. The hardness and elastic modulus were determined from the indentation depth of the unloading curve. To eliminate any influence of the substrate
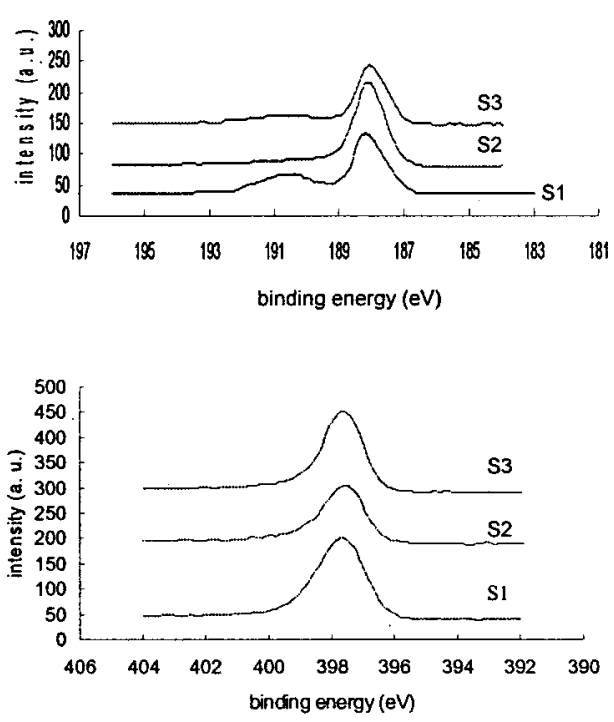

FIG. 1. (a) $\mathrm{B}_{1 s}$ and (b) $\mathrm{N}_{1 s}$ XPS spectra for CrBN films.
TABLE II. Relative phase composition determined from XPS measurements.

\begin{tabular}{ccc}
\hline \hline Sample & $\% \mathrm{~B}$ as Cr-B & $\% \mathrm{~B}$ as BN \\
\hline S1 & 72 & 28 \\
S2 & 95 & 5 \\
S3 & 88 & 12 \\
\hline \hline
\end{tabular}

material on the measurement of Young's modulus, the penetration range of the indenter was limited to a depth $<0.1 d$, where $d$ is the film thickness.

\section{EXPERIMENTAL RESULTS}

\section{A. Chemical analysis}

XPS spectra were recorded before and after sputter etching with an emphasis on peaks associated with $\mathrm{Cr}_{2 p}, \mathrm{~B}_{1 s}$, and $\mathrm{N}_{1 s}$. Carbon and oxygen peaks were also observed prior to sputter etching. These peaks are due to surface contamination. The elemental composition of the coatings determined from peak area measurements are as follows: sample $\mathrm{S} 1$ is $43 \% \mathrm{Cr}, 37 \% \mathrm{~B}$, and $20 \% \mathrm{~N}$; S2 is $50 \% \mathrm{Cr}, 43 \% \mathrm{~B}$, and $7 \% \mathrm{~N}$; and $\mathrm{S} 3$ is $56 \% \mathrm{Cr}, 25 \% \mathrm{~B}$, and $19 \% \mathrm{~N}$.

The binding energies of the core level peaks obtained from "standard" binary $\left(\mathrm{CrB}_{2}, \mathrm{CrB}, \mathrm{Cr}_{2} \mathrm{~B}, \mathrm{Cr}_{2} \mathrm{~N}, \mathrm{CrN}\right.$, and $\mathrm{BN}$ ) compounds are given in Table I. ${ }^{25}$ Figures 1(a) and 1(b) show $\mathrm{B}_{1 s}$ and $\mathrm{N}_{1 s}$ spectra, respectively. The electron binding energy profile of $\mathrm{B}$ shows a broad peak at about $188.0 \mathrm{eV}$. This peak consists of two components that correspond to $\mathrm{Cr}-\mathrm{B}\left(\mathrm{Cr}_{2} \mathrm{~B}\right.$ at $187.5 \mathrm{eV}, \mathrm{CrB}$ at $187.7 \mathrm{eV}$, and $\mathrm{CrB}_{2}$ at 188.0 $\mathrm{eV})$, and $\mathrm{BN}(190.5 \mathrm{eV}) .{ }^{25}$ The $\mathrm{Cr}-\mathrm{B}$ components for $\mathrm{S} 1$ and $\mathrm{S} 3$ were identified and were found to correspond to $\mathrm{Cr}_{2} \mathrm{~B}$. For S2, however, the binding energy of the $\mathrm{Cr}-\mathrm{B}$ component had a higher value, which corresponds to $\mathrm{CrB}$. The nitrogen peak may be described by the superposition of three peaks centered at 396.7, 397.4, and $398.1 \mathrm{eV}$ that correspond to $\mathrm{CrN}, \mathrm{Cr}_{2} \mathrm{~N}$, and $\mathrm{BN}$, respectively. ${ }^{25}$ The $\mathrm{B}_{1 s}$ and $\mathrm{N}_{1 s}$ peaks were curve fitted to determine the percentage of $\mathrm{B}$ bonded as $\mathrm{BN}$ and $\mathrm{Cr}-\mathrm{B}$ and $\mathrm{N}$ bonded as $\mathrm{BN}$ and $\mathrm{Cr}-\mathrm{N}$ (Tables II and III).

A quantitative fit of the $\mathrm{Cr}_{2 p}$ peak to obtain the relative concentration of $\mathrm{Cr}-\mathrm{B}$ and $\mathrm{Cr}-\mathrm{N}$ was not attempted due to the known difficulties in doing so for CrN coatings. However, it is worthwhile to examine this peak qualitatively to substantiate the results collected so far. The electron binding energy profile of $\mathrm{Cr}$ exhibited two major peaks that correspond to $\mathrm{Cr}-\mathrm{B}$ (574-575 eV depending on the stoichiometry) and $\mathrm{Cr}-\mathrm{N}\left(575.8 \mathrm{eV}\right.$ for $\mathrm{CrN}$ and $577.7 \mathrm{eV}$ for $\left.\mathrm{Cr}_{2} \mathrm{~N}\right){ }^{25}$ XPS may be used to identify the structural form of the BN phase. ${ }^{26}$ Unlike $c$-BN or amorphous BN $(a-\mathrm{BN}), h-\mathrm{BN}$ ex-

TABLE III. Relative phase composition determined from XPS measurements.

\begin{tabular}{cccc}
\hline \hline Sample & $\% \mathrm{~N}$ as $\mathrm{CrN}$ & $\% \mathrm{~N}$ as $\mathrm{Cr}_{2} \mathrm{~N}$ & $\% \mathrm{~N}$ as BN \\
\hline S1 & 0 & 52 & 48 \\
$\mathrm{~S} 2$ & 0 & 72 & 28 \\
$\mathrm{~S} 3$ & 0 & 75 & 25 \\
\hline \hline
\end{tabular}




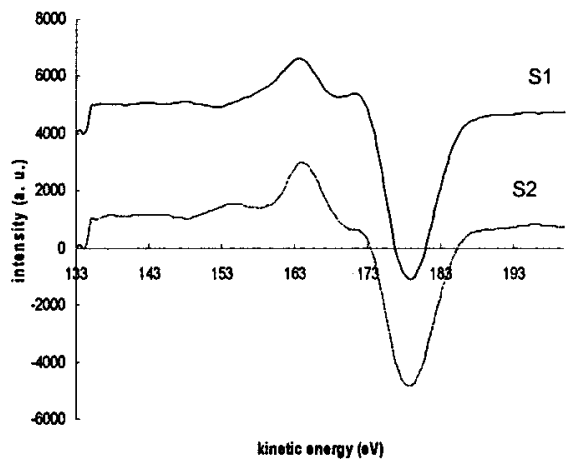

FIG. 2. Differential AES spectra showing the B KLL region for CrBN coatings.

hibits a shakeup satellite peak located $9 \mathrm{eV}$ after the $\mathrm{B}_{1 s}$ and $\mathrm{N}_{1 s}$ peaks. ${ }^{27}$ XPS data were recorded in the $\mathrm{B}_{1 s}$ energy loss region for the three $\mathrm{CrBN}$ samples. A strong satellite peak was observed for sample S1, a weaker one for S3, and no satellite peak for $\mathrm{S} 2$. This suggests the presence of $h$ - BN in $\mathrm{S} 1$ and $\mathrm{S} 3$. In S2, BN is present in very small quantities and may be amorphous.

AES spectra for the $\mathrm{CrBN}$ samples were recorded for samples S1 and S2. The chemical composition of the coatings was determined from peak height measurements: $49 \%$ $\mathrm{Cr}, 32 \% \mathrm{~B}$, and $19 \% \mathrm{~N}$ for $\mathrm{S} 1$ and $52 \% \mathrm{Cr}, 42 \% \mathrm{~B}$, and $6 \%$ $\mathrm{N}$ for S2. Shown in Fig. 2 are the Auger B KLL spectra for samples $\mathrm{S} 1$ and $\mathrm{S} 2$. The spectrum for sample $\mathrm{S} 2$ is consistent with the $\mathrm{KL}_{23} \mathrm{~L}_{23}$ transition for $\mathrm{Cr}-\mathrm{B}$ in agreement with the XPS data in the previous section (Table II). The peak shape of sample S1 corresponds to a combination of the B KLL peaks from both $\mathrm{BN}$ and $\mathrm{Cr}-\mathrm{B}$. The two peaks directly below the $\mathrm{KL}_{23} \mathrm{~L}_{23}$ peak at $179.0 \mathrm{eV}$ (i.e., at 158.5 and 148.0 $\mathrm{eV})$ correspond to $h-\mathrm{BN}$ rather than $c-\mathrm{BN}$, which are at much lower energies. ${ }^{26}$ The AES spectrum for sample S3 was similar to that of $\mathrm{S} 1$ and consisted in a combination of $\mathrm{B}$ KLL peaks from both $h$-BN and $\mathrm{Cr}-\mathrm{B}$.

\section{B. Structural analysis}

XRD data for the three CrBN samples were recorded. The XRD data revealed the presence of wide peaks with low intensity typical for nanocrystalline materials, as shown in Fig. 3 for sample S1. The diffraction peaks are so broad that a conclusive phase identification is impossible. AFM images

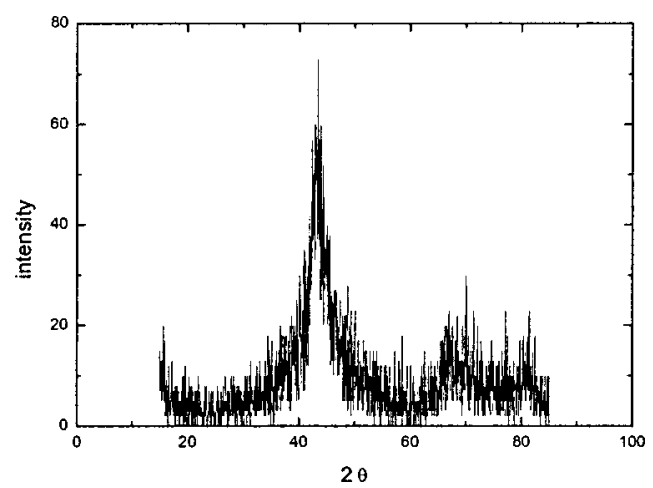

FIG. 3. X-ray diffraction data for sample S1.

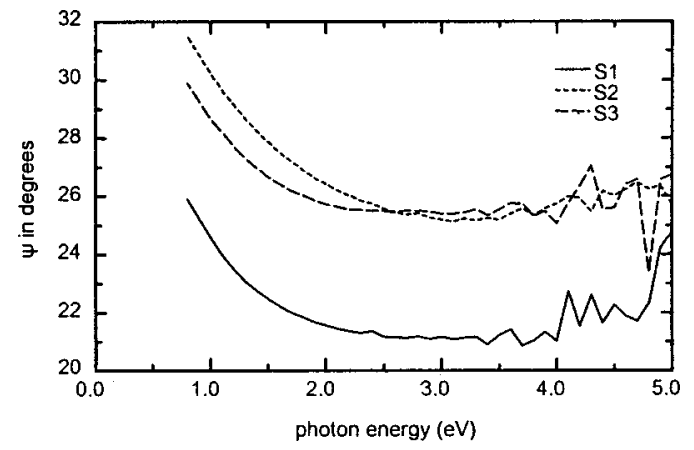

FIG. 4. VIS-SE spectra for CrBN films taken with an angle of incidence of $70^{\circ}$.

were taken for these samples. The surface morphology consisted of domed rounded columnar structure similar to the zone 1 microstructure of Thornton's model. Upon closer examination of this sample, additional surface features were observed on the individual columns. Each single column was found to consist of smaller nanostructural grains. The average grain size, determined by line scan measurements across the "troughs" of the grain structure, varied from $8 \pm 2 \mathrm{~nm}$. The surface roughness was measured to be $1.0 \pm 0.2 \mathrm{~nm}$.

\section{Optical analysis}

Ellipsometric (VIS-SE) spectra were taken with angles of incidence of $65^{\circ}, 70^{\circ}$, and $75^{\circ}$. Figure 4 shows the measured $\psi$ values as a function of photon energy for the three samples taken with an angle of incidence of $70^{\circ}$. The fitting of the ellipsometric data requires the knowledge of the optical constants for the constituent phases. All possible phase combinations were listed in the introduction. The refractive indices for $\mathrm{BN}$ (both in the hexagonal and cubic forms) are available in the literature. ${ }^{28}$ The refractive indices for $\mathrm{Cr}$, $\mathrm{Cr}_{2} \mathrm{~N}$, and $\mathrm{CrN}$ were recently established by Mihut. ${ }^{29} \mathrm{How}-$ ever, the optical constants for the $\mathrm{Cr}-\mathrm{B}$ phases $\left(\mathrm{Cr}_{2} \mathrm{~B}, \mathrm{CrB}\right.$, $\mathrm{CrB}_{2}, \mathrm{CrB}_{4}$, and $\mathrm{Cr}_{5} \mathrm{~B}_{3}$ ) are not readily available in the literature. We were able to grow a near-stoichiometric $\mathrm{Cr}_{2} \mathrm{~B}$ coating in our deposition chamber, as verified by AES $[\mathrm{Cr}$ $(65 \pm 3 \%)$ and $\mathrm{B}(35 \pm 3 \%)]$. Its ellipsometric spectrum was subsequently recorded (Fig. 5). The SE data for this sample were used to determine the dielectric function of pure $\mathrm{Cr}_{2} \mathrm{~B}$. Fresnel equations were employed to calculate the reflections

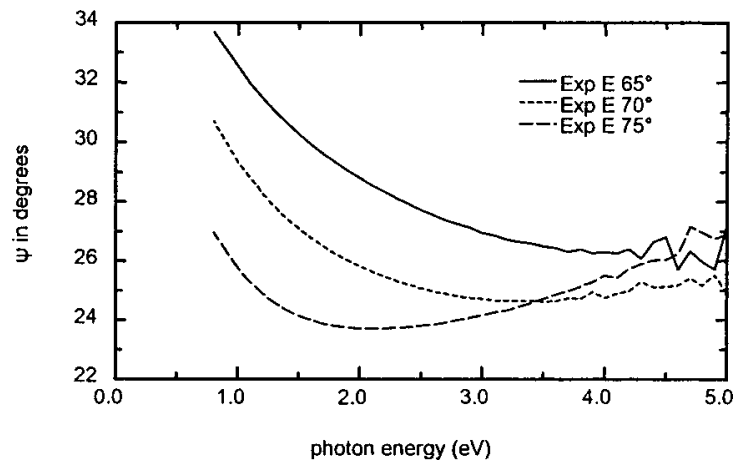

FIG. 5. VIS-SE spectra for $\mathrm{CrB}_{2}$ film taken with an angle of incidence of $70^{\circ}$. 


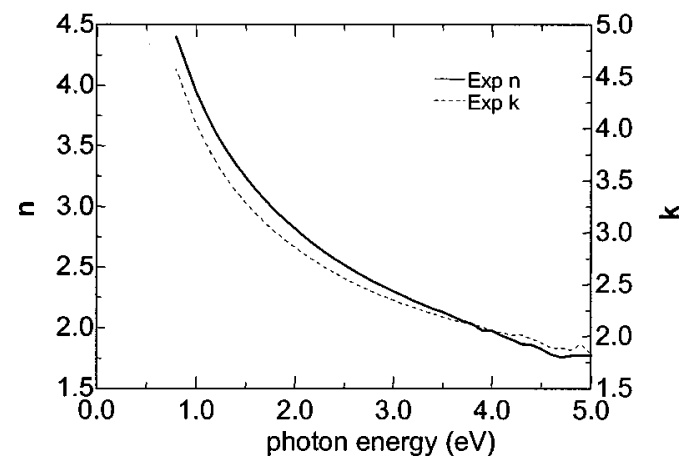

FIG. 6. Optical constants $n$ and $k$ for $\mathrm{CrB}_{2}$ film.

at interfaces and minimized the difference between the experimental and the fitted data. ${ }^{17} \mathrm{~A}$ two-parameter model was used with the refractive index, $n$, and the extinction coefficient, $k$, varied to obtain the best fit. The following mean square error (MSE) was then minimized:

$$
\mathrm{MSE}=\frac{1}{2 N-M} \sum_{i=1}^{N}\left[\left(\frac{\psi_{i}^{\bmod }-\psi_{i}^{\exp }}{\sigma_{\psi, i}^{\exp }}\right)^{2}+\left(\frac{\Delta_{i}^{\bmod }-\Delta_{i}^{\exp }}{\sigma_{\Delta, i}^{\exp }}\right)^{2}\right],
$$

where $N$ is the number of $(\psi, \Delta)$ pairs, $M$ is the number of variable parameters in the model, and $\sigma$ is the standard deviation on the experimental data points $\left(\sigma_{\psi}=\sigma_{\Delta}=0.05\right.$ degrees). The MSE was found to be 0.44 . The optical constants $n$ and $k$ that best fit the data are shown in Fig. 6.

The ellipsometric data in Fig. 4 were fitted using a single layer model since the $\mathrm{CrBN}$ layer was optically thick. The layer was simulated as a mixture of three phases based on $\mathrm{Cr}-\mathrm{B}, \mathrm{Cr}-\mathrm{N}$, and $\mathrm{B}-\mathrm{N}$ with the Bruggeman effective medium approximation (EMA). ${ }^{30}$ The EMA is relevant for a random aggregate structure, which is useful for describing films prepared by sputtering or evaporation. The best fit parameters and $90 \%$ confidence limits for sample S1 were found to be $(51 \% \pm 3 \%) \mathrm{Cr}_{2} \mathrm{~B}+(23 \% \pm 2 \%) \mathrm{CrN}+(26 \%$ $\pm 1 \%) h$-BN and for sample $\mathrm{S} 3(74 \% \pm 6 \%) \mathrm{Cr}_{2} \mathrm{~B}+(14 \%$ $\pm 4 \%) \mathrm{Cr}_{2} \mathrm{~N}+(12 \% \pm 2 \%) h$-BN. The MSEs were 1.3 and 1.9 for samples $\mathrm{S} 1$ and $\mathrm{S} 3$, respectively. The elemental composition were deduced from the phase compositions: $46 \% \mathrm{Cr}$, $30 \% \mathrm{~B}$, and $26 \% \mathrm{~N}$ for $\mathrm{S} 1$ and $59 \% \mathrm{Cr}, 30 \% \mathrm{~B}$, and $11 \% \mathrm{~N}$ for S3. These results suggest that SE and XPS are in agreement and that $\mathrm{BN}$ crystallized primarily in the hexagonal form. We were unable to obtain a good fit for sample S2. XPS data in Sec. III A suggested that the constituent phases of this sample were $\mathrm{CrB}, \mathrm{Cr}_{2} \mathrm{~N}$, and $h$ - BN. The refractive index for stoichiometric $\mathrm{CrB}$ is therefore required to adequately fit the ellipsometric data for S2.

Ellipsometry requires different instruments depending on the nature of the radiation used. VIS-SE uses visible light $(0.3-0.7 \mu \mathrm{m})$, which can eventually be extended towards the near UV $(0.2-0.3 \mu \mathrm{m})$ and the near IR $(0.7-1.7 \mu \mathrm{m})$. IR-SE uses mid- and far-IR radiation $(1.7-30 \mu \mathrm{m})$. Both techniques complement each other. The refractive index in the visible is essentially determined by the electric and dielectric properties of the materials. In the IR, however, chemical bonds

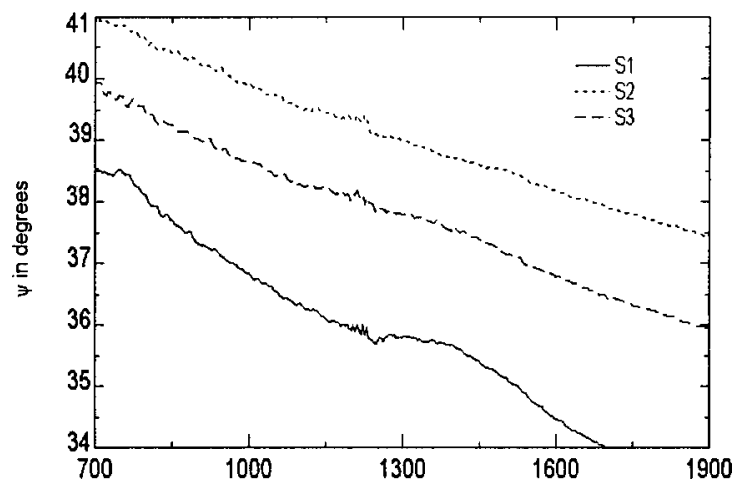

FIG. 7. IR-SE spectra for $\mathrm{CrBN}$ films taken with an angle of incidence of $70^{\circ}$.

cause additional characteristic absorption peaks in the spectrum, which are very helpful in the phase identification process.

Fourier transform infrared spectroscopy (FTIR) is widely used to investigate the phases in $\mathrm{BN}$ films because of its high capability to distinguish between $s p^{3}$ and $s p^{2}$ bonds. ${ }^{31}$ Geike et al. ${ }^{32}$ observed two characteristic $h$-BN lattice resonance absorptions for electric field polarizations $E$ parallel (out of plane:\|) and perpendicular (in-plane: $\perp$ ) to the lattice $c$ axis, characterized by their transverse (TO) and longitudinal (LO) optical frequencies $\omega_{\mathrm{TO} \|}$ $=783 \mathrm{~cm}^{-1}, \quad \omega_{\mathrm{LO} \|}=823 \mathrm{~cm}^{-1}, \quad \omega_{\mathrm{TO} \perp}=1367 \mathrm{~cm}^{-1}, \quad$ and

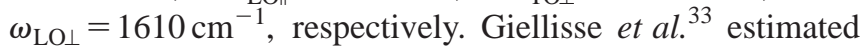
the characteristic $c$-BN lattice absorptions at resonance frequencies of $\omega_{\mathrm{TO}_{c}}=1065 \mathrm{~cm}^{-1}$ and $\omega_{\mathrm{LO}_{c}}=1340 \mathrm{~cm}^{-1}$. Figure 7 shows a series of IR-SE spectra for the three CrBN samples. Strong peaks characteristic of $h$-BN phonon mode resonance were observed for sample S1. These peaks were very broad due to the small grain size of these phases. ${ }^{34}$ These phonon peaks were very weak for sample S3 and nonexistent for sample $\mathrm{S} 2$. These observations were very similar to those made by XPS data recorded in the $\mathrm{B}_{1 s}$ energy loss region (Sec. III A).

\section{Mechanical analysis}

The film hardness for the three CrBN samples was measured. A total of five indentations were performed for each load $(5000 \mu \mathrm{N})$ and the mean values and standard deviation of hardness and elastic modulus computed. The measured hardness values for all three samples were in the same range and varied from 19 to $22 \mathrm{GPa}$. The standard variations varied from 0.3 to $0.5 \mathrm{GPa}$. The elastic moduli were all in the 240 $\mathrm{GPa}$ range with a standard deviation in the $3 \mathrm{GPa}$ range.

\section{E. Discussion}

Four techniques were used to characterize the chemical and/or structural composition of our ceramic nitride coatings, namely: x-ray photoelectron spectroscopy, Auger electron spectroscopy, x-ray diffraction, and spectroscopic ellipsometry. XPS and AES are excellent techniques to determine chemical bonds between different elements in a compound material. However, they are surface techniques that probe 
only the topmost $5 \mathrm{~nm}$ of a given material and are substantially affected by surface impurities and oxides. Sputter etching of the surface would solve this problem, but is a destructive technique that may lead to erroneous results due to preferential sputtering of certain elements. The disadvantage of XRD is that it is more of a qualitative technique and is does not provide accurate information for nanocrystalline films. Another technique that could have been attempted is RBS. RBS probes much deeper into the sample as compared to XPS or AES. However, it is not sensitive to small B and N variations. SE has rarely been used for ternary nitride coatings prior to this work. SE is a nondestructive technique and shows promise as an analysis technique for these types of materials. However, it requires the accurate knowledge of the optical constants of the constituent phases for multiphase materials. In this study, SE, XPS, and AES gave analogous results. In situ ellipsometry might be an excellent candidate for real-time monitoring and control during the deposition of MBN coatings. By accurately controlling the deposition process, the enormous postgrowth analysis time normally needed to reproducibly produce nitride coatings could be reduced and more rapid setup of a new system for the deposition of these coatings could also be facilitated. Industry would greatly benefit from the control of the phase composition of such versatile structures.

\section{CONCLUSIONS}

This article presents an attempt to fabricate and analyze CrBN coatings using ion beam assisted deposition. The elemental and phase compositions were deduced from a combination of XPS, AES, and VIS-SE analyses. These techniques revealed that the phase composition for these samples were: $\left(\mathrm{Cr}_{2} \mathrm{~B}+\mathrm{CrN}+\mathrm{BN}\right)$ for sample $\mathrm{S} 1,\left(\mathrm{CrB}+\mathrm{Cr}_{2} \mathrm{~N}+\mathrm{BN}\right)$ for $\mathrm{S} 2$, and $\left(\mathrm{Cr}_{2} \mathrm{~B}+\mathrm{Cr}_{2} \mathrm{~N}+\mathrm{BN}\right)$ for $\mathrm{S} 3$. In addition, the crystalline structure of $\mathrm{BN}$ appears to be primarily $h$ - $\mathrm{BN}$ from XPS, AES, and IR-SE measurements. In situ ellipsometry may be a potential technique to be used in real time during the production of these and similar ternary nitride structures with controlled composition and hence controlled mechanical properties.

\section{ACKNOWLEDGMENTS}

The authors would like to thank Professor I. Petrov and Dr. R. Haash of the University of Illinois Champaign-Urbana for providing XPS, RBS, and nanoindentation facilities, supported by the U.S. Department of Energy under Grant No. DEFG02-96-ER45439. Acknowledgement is extended to J. Martin of the Science Library at the University of Arizona for providing the $\mathrm{CrBN}$ phase diagram. This work was sponsored by NSF (CMS- 9358108) and (CMS-9978789), and by the University of Nebraska-Lincoln Center for Materials Research and Analysis and the Center for Microelectronics and
Optical Materials Research. Additionally, R. Nilchiani and J. A. Turner wish to acknowledge the support of the Air Force Office of Scientific Research under Grant No. F49620-99-10254 and the Center for Electro-Optics at the University of Nebraska-Lincoln. The work at Spire Corporation was funded in part by a SBIR Grant from NIH/NIAMS.

${ }^{1}$ C. Gautier and J. Machet, Thin Solid Films 295, 43 (1997).

${ }^{2}$ Y. L. Su and S. H. Yao, Wear 205, 112 (1997).

${ }^{3}$ J. D. Demaree, C. G. Fountzoulas, and J. K. Hirvonen, Surf. Coat. Technol. 86-87, 309 (1996).

${ }^{4}$ B. Matthes, E. Broszeit, and K. H. Kloos, Surf. Coat. Technol. 57, 97 (1993).

${ }^{5}$ O. Knotek, R. Breidenbach, F. Jungblut, and F. Loffler, Surf. Coat. Technol. 43/44, 107 (1990).

${ }^{6}$ R. Wiedemann, V. Weihnacht, and H. Oettel, Surf. Coat. Technol. 116119, 302 (1999).

${ }^{7}$ C. Rebholz, J. M. Schneider, A. A. Voevodin, J. Steinebrunner, C. Charitidis, S. Logothetidis, A. Leyland, and A. Matthews, Surf. Coat. Technol. 113, 126 (1999)

${ }^{8}$ C. Mitterer, P. Rodhammer, H. Stori, and F. Jeglitsch, J. Vac. Sci. Technol. A 7, 2646 (1989).

${ }^{9}$ C. Mitterer, A. Ubleis, and R. Ebner, Mater. Sci. Eng., A 140, 670 (1991).

${ }^{10}$ C. Héau and J. P. Terrat, Surf. Coat. Technol. 108-109, 332 (1998).

${ }^{11}$ P. Hammer, A. Steiner, R. Villa, M. A. Baker, P. N. Gibson, J. Haupt, and W. Gissler, Surf. Coat. Technol. 68/69, 194 (1994).

${ }^{12}$ B. Rother and H. Kappl, Surf. Coat. Technol. 73, 14 (1995).

${ }^{13}$ B. Rother and H. Kappl, Surf. Coat. Technol. 96, 163 (1997).

${ }^{14}$ P. Rogl and J. C. Schuster, Phase Diagrams of Ternary Boron Nitride and Silicon Nitride Systems (ASM, Materials Park, OH, 1992), p. 20.

${ }^{15}$ H. Fujiwara, J. Koh, and R. W. Collins, Thin Solid Films 313-314, 474 (1998).

${ }^{16}$ M. Gioti, S. Logothedis, P. Patsalas, A. Laskaraskis, Y. Panayiotatos, and V. Kechagias, Surf. Coat. Technol. 125, 289 (2000).

${ }^{17}$ S. M. Aouadi, D. M. Schultze, S. L. Rohde, K. C. Wong, and K. A. R. Mitchell, Surf. Coat. Technol. 140, 269 (2001).

${ }^{18}$ S. Logothedis, I. Alexandrou, and N. Vouroutzis, Thin Solid Films 275, 44 (1996).

${ }^{19}$ X. Gao, D. W. Glenn, and J. A. Woollam, Thin Solid Films 313-314, 511 (1998).

${ }^{20}$ X. Gao, J. Hale, S. Heckens, and J. A. Woollam, J. Vac. Sci. Technol. A 16, 429 (1998).

${ }^{21}$ E. Luken, E. Ziegler, and M. Lingham, Proc. SPIE 2873, 113 (1996).

${ }^{22}$ M. S. Aouadi, A. Kleinschmidt, G. A. Clarke, N. R. Osborne, R. R. Parsons, and L. B. Da Silva, Thin Solid Films 303, 53 (1997).

${ }^{23}$ J. A. Woollam Co. Inc., Guide to Using WVASE32 (Lincoln, NE, 1997).

${ }^{24}$ R. M. A. Azzam and N. M. Bashara, Ellipsometry and Polarized Light (Elsevier, New York, 1987).

${ }^{25}$ C. D. Wagner, Handbook of XPS (Physical Electronics, Minnesota, 1995).

${ }^{26}$ M. A. Baker, T. P. Mollart, P. N. Gibson, and W. Gissler, J. Vac. Sci. Technol. A 15, 284 (1997).

${ }^{27}$ R. Trehan, Y. Lifshitz, and J. W. Rabalais, J. Vac. Sci. Technol. A 8, 4026 (1990).

${ }^{28}$ Handbook of Optical Constants, edited by E. D. Palik (Academic, New York, 1998), Vol III.

${ }^{29}$ D. M. Mihut, M. Sc. thesis, The University of Nebraska-Lincoln, 1999.

${ }^{30}$ D. A. G. Bruggeman, Ann. Phys. 24, 636 (1935).

${ }^{31}$ A Bonizzi, R. Checchetto, A. Miotello, and P. M. Ossi, Europhys. Lett. 44, 627 (1998).

${ }^{32}$ R. Geick, C. H. Perry, and G. Rupprecht, Phys. Rev. 146, 543 (1966).

${ }^{33}$ P. J. Gielisse, S. S. Mitra, J. N. Plendl, R. D. Griffis, L. C. Mannsur, R. Marshall, and E. A. Pascoe, Phys. Rev. 155, 1039 (1967).

${ }^{34}$ E. Franke, M. Schubert, H. Neumann, T. E. Tiwald, D. W. Thompson, J. A. Woollam, J. Hahn, and F. Richter, J. Appl. Phys. 82, 2906 (1997). 